\title{
New insights into saline water evaporation from porous media: Complex interaction between evaporation rates, precipitation and surface temperature
}

DOI:

10.1002/2017GL073337

\section{Document Version}

Accepted author manuscript

Link to publication record in Manchester Research Explorer

Citation for published version (APA):

Shokri, S., Vetter, T., Webb, C., \& Shokri, N. (2017). New insights into saline water evaporation from porous media: Complex interaction between evaporation rates, precipitation and surface temperature. Geophysical Research Letters, 44(11), 5504-5510. https://doi.org/10.1002/2017GL073337

Published in:

Geophysical Research Letters

\section{Citing this paper}

Please note that where the full-text provided on Manchester Research Explorer is the Author Accepted Manuscript or Proof version this may differ from the final Published version. If citing, it is advised that you check and use the publisher's definitive version.

\section{General rights}

Copyright and moral rights for the publications made accessible in the Research Explorer are retained by the authors and/or other copyright owners and it is a condition of accessing publications that users recognise and abide by the legal requirements associated with these rights.

\section{Takedown policy}

If you believe that this document breaches copyright please refer to the University of Manchester's Takedown Procedures [http://man.ac.uk/04Y6Bo] or contact uml.scholarlycommunications@manchester.ac.uk providing relevant details, so we can investigate your claim.

\section{OPEN ACCESS}




\section{New insights into saline water evaporation from porous media: Complex interaction}

\section{between evaporation rates, precipitation and surface temperature \\ Salomé M.S. Shokri-Kuehni, Thomas Vetter, Colin Webb, Nima Shokri*}

School of Chemical Engineering and Analytical Science, The University of Manchester,

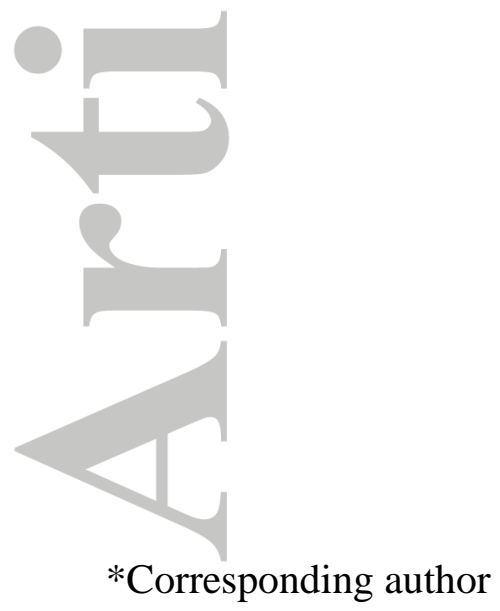

Manchester, UK

Dr. Nima Shokri

School of Chemical Engineering and Analytical Science

Room C26, The Mill

The University of Manchester

Sackville Street, Manchester, M13 9PL, UK

Tel: 0441613063980

Email: nima.shokri@manchester.ac.uk

Group website: http://personalpages.manchester.ac.uk/staff/nima.shokri/

This article has been accepted for publication and undergone full peer review but has not been through the copyediting, typesetting, pagination and proofreading process which may lead to differences between this version and the Version of Record. Please cite this article as doi: 10.1002/2017GL073337 


\begin{abstract}
Understanding salt transport and deposition patterns during evaporation from porous media is important in many engineering and hydrological processes such as soil salinization, ecosystem functioning and land-atmosphere interaction. As evaporation proceeds, salt concentration increases until it exceeds solubility limits, locally, and crystals precipitate. The interplay between transport processes, crystallization and evaporation influences where crystallization occurs. During early stages, the precipitated salt creates an evolving porous structure affecting the evaporation kinetics. We conducted a comprehensive series of experiments to investigate how the salt concentration and precipitation influence evaporation dynamics. Our results illustrate the contribution of the evolving salt crust to the evaporative mass losses. High-resolution thermal imaging enabled us to investigate the complex temperature dynamics at the surface of precipitated salt, providing further confirmation of salt crust contribution to the evaporation. We identify different phases of saline water evaporation from porous media with the corresponding dominant mechanisms in each phase and extend the physical understanding of such processes.
\end{abstract}




\section{Introduction}

Evaporation of saline water from porous media is important in many environmental, engineering and hydrological processes including vegetation and plant growth, soil salinization, land-atmosphere interaction, functioning of the eco-system and crop production [Rodriguez-Navarro and Doehne, 1999; Suweis et al., 2010; Ott et al., 2015; Bergstad and Shokri, 2016]. This has motivated many researchers to investigate various aspects of this process including the effects of grain size, wettability, heterogeneity and external conditions

[Huinink et al., 2002; Guglielmini et al., 2008; Nachshon et al., 2011a, 2011b; Eloukabi et al. 2013; Norouzi Rad et al., 2015; Jambhekar et al., 2015; Börnhorst et al., 2016; Dai et al., 2016; Shokri-Kuehni et al., 2017].

Saline water evaporation is influenced by transport properties of the porous media, properties of the evaporating solution, external conditions (wind, radiation, ambient temperature and relative humidity), and by the precipitation of salt crystals [Norouzi Rad et al., 2013; Shokri, 2014; Jambhekar et al., 2015; Shokri-Kuehni et al., 2017]. During evaporation, solute is transported, via capillary induced liquid flow, from a wet zone to the evaporation surface resulting in increasing solute concentration close to the vaporization plane [Guglielmini et al., 2008]. At the same time diffusion tends to spread the salt homogenously through the entire space. This competition between advection and diffusion (quantified by the Peclet number $P e$ ) determines the solute distribution during the evaporation process [Guglielmini et al., 2008; Shokri, 2014] when no salt crystallization occurs.

When the salt concentration substantially exceeds the solubility limit (i.e., supersaturation exceeds a critical value) [Desarnaud et al., 2014], crystals will precipitate by first nucleating and then growing. When advection dominates (i.e., when $P e>>1$ ), the concentration of salt in the liquid phase is the highest at the surface of the porous media and hence precipitation 
occurs preferentially at this surface which is called efflorescence. Depending on external conditions, temperature and humidity, the crystals formed at the surface create complex, branching structures (originating from epitaxial growth and the formation of dendrites), which can substantially increase the surface area available for evaporation. Furthermore, evaporation and crystallization give rise to heat effects: the crystallization of common salts releases heat, while evaporation of water requires heat. This can therefore lead to hot or cold spots at the surface of the porous media depending on the rate of heat transfer with the surroundings. How exactly the precipitated salt at the surface or within the pores of porous media modifies the capillary liquid flow supplying the evaporative demand is not well understood.

One of the key factors influencing the evaporation process is the salt concentration [Norouzi Rad and Shokri, 2012; Gupta et al., 2014] . When the porous media surface is wet, the evaporation rate $e$ is related to the difference between the saturated vapour pressure $P_{S}$ above the surface and the vapour pressure in air $P_{\infty}\left(P_{\infty}=R H \times P_{S}\right.$ where $\mathrm{RH}$ indicates relative humidity). One would expect the evaporation rate to decrease as initial salt concentration increases, owing to the impact of salt concentration on lowering $P_{S}$. However, some recent experimental studies show that increasing salt concentration does not necessarily reduce the evaporation rate [Sghaier and Prat, 2009; Norouzi Rad and Shokri, 2012; Gupta et al., 2014]. A commonly used scenario to describe this paradoxical behaviour is to (qualitatively) relate the evaporation rate to the increased surface area due to efflorescence [Sghaier and Prat, 2009].

Despite advances in analysis of saline water evaporation from porous media, the understanding of how exactly efflorescence and salt concentration influences the drying rate and dynamics is surprisingly not very advanced. This aspect has rarely been elaborated in the 
literature partly due to the complexity of the processes involved. Without such knowledge, our modelling efforts will be largely dependent on adjusting parameters. Motivated by their importance in various applications, the specific objectives of the present study were to investigate how salt concentration and efflorescence influence the drying curve and illustrate some of the challenges involved in describing saline water evaporation from porous media.

\section{Experimental considerations}

The influence of initial salt concentration and surface salt precipitation on drying rate and the corresponding surface temperature dynamics were investigated by conducting a series of evaporation experiments. Cylindrical glass columns $(150 \mathrm{~mm}$ in height, $80 \mathrm{~mm}$ diameter with all boundaries closed except the top, which was exposed to air) were packed with quartz sand grains with average particle size of $0.27 \mathrm{~mm}$. The sand packs were wetted with $\mathrm{NaCl}$ solutions of different concentrations ranging from 0.05 to $3.5 \mathrm{M}$. Additionally, one column was packed with solid $\mathrm{NaCl}$ grains and wetted with saturated $\mathrm{NaCl}$ solution. The columns were mounted on digital balances (resolution of $0.01 \mathrm{~g}$ ) to record the mass loss due to evaporation over time. Moreover, one column was filled with pure water to measure the potential evaporation rate in the absence of any salt in each round of experiments. The ambient temperature and relative humidity were measured using two standard relative humidity and temperature sensors (HygroClip HC2-S, Rotronic Instrument Corp.). Metal halide lamps (EYE Color Arc PAR36, Iwasaki Electronic Co., Japan) were directed onto the surface of the packed columns (with an arrangement similar to that illustrated in ShokriKuehni et al. [2016]) to boost the evaporation process. To obtain the temporal and spatial evolution of the surface temperature [Aminzadeh and Or, 2014; Haghighi and Or, 2015], a

thermal camera (FLIR T650sc, FLIR Systems, Inc.) was fixed above sand columns and set to record an image every minute. Additionally an imaging system was set up to take visual 
snapshots of the surface of sand columns every $30 \mathrm{~min}$. Furthermore, growth dynamics and structure of salt crust forming on the surface during the evaporation process was investigated in a separate experiment, using an optical microscope (LeiCaM205C, 20.5:1 zoom, 0.952 mm resolution) equipped with a high-resolution digital camera (LeiCaDFC 3000G) set to record an image every minute.

\section{Results and discussions}

\subsection{Challenges of describing saline water evaporation from porous media}

Figure 1 (a) shows the evaporative mass losses at different times as a function of the initial salt concentration. In Figure 1 (b) typical examples of precipitation patterns at the surface of the columns are shown at different times from the onset of the experiments.

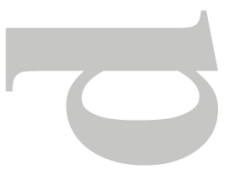

There are a few features in Figure 1 that illustrate the complexity of saline water evaporation from porous media. The first puzzling behaviour is the relationship between evaporative mass losses and the initial salt concentrations. According to Raoult's law, one would expect to observe decreasing evaporative mass losses as the solute concentration increases especially when the surface is still wet (thus the evaporation rate is dependent on the saturated vapour pressure and controlled by the external conditions). However this is not the general trend observed in Figure 1(a) across the wide range of concentrations studied. Similar behaviour has recently been reported in other studies [Sghaier and Prat, 2009; Norouzi Rad and Shokri, 2012; Gupta et al., 2014].

The formation of salt crusts at top of sand columns as detailed in Figure 1 (b), e.g. for the 3.5 M salt concentration, does not stop, or even slow down the evaporation shown in Figure 1 (a). In fact, the cumulative mass loss almost doubled, in this case, from 58.1g at 3 days to 
$112.0 \mathrm{~g}$ after 8 days. This observation exemplifies the complex interplay of effects and, clearly, the question of what is controlling the evaporation rate, in addition to the salt concentration or the atmospheric conditions, is paramount for any accurate predictions of the process.

Figure 2 shows the measured evaporation rates from the sand columns saturated with varying initial salt concentrations versus time (the evaporation rate was scaled by the potential evaporation rate, i.e., the one observed in the drying experiment carried out in the absence of salt). The observed fluctuation in the measured evaporation rate from the sand column saturated with pure water at the early stage might be due to the fluctuation of the external conditions (ambient temperature and relative humidity). Figure 2 shows the columns with notably different initial concentrations and surface precipitation patterns may have very close evaporative fluxes. For example, sand columns saturated with 0.5 and $2.5 \mathrm{M}$ experience essentially similar drying rate after $\sim 3.5$ days from the onset of the experiment which is not an intuitive result. Next, we will discuss about the possible reason behind this behaviour.

\subsection{Effects of the precipitated salt at the surface on the evaporative fluxes}

Closer inspection of drying curves in Figure 2 and surface precipitation patterns presented in

Figure 1 (b) indicates that precipitated salt covering the surface of the column does not necessarily initiate the diffusive-controlled evaporation through the salt layer. For example, in the case of the column wetted with $0.2 \mathrm{M} \mathrm{NaCl}$ solution, although the surface of the sand column is covered by salt after $\sim 5$ days, for a long time after this the evaporation rate remains much higher than expected from a diffusive-controlled flux through the dry salt crust. Comparing the measured evaporation rates with the recorded dynamics of the precipitation patterns at the surface confirm the significant contribution of the precipitated salt to the 
evaporative fluxes (see for example Figure 1(b) at 3.5 $\mathrm{M}$ and the corresponding curve in Figure 1(a)). Interestingly the evaporation rate measured from the column packed with salt grains saturated with salty solution is very similar to the evaporation rate measured from the sand columns saturated with salty solutions with varying initial concentrations. This is an important result because it shows that the evaporation rates might be controlled by the porous structure and dynamics of the precipitated salt formed at the surface. This explains why the measured rates in the early stages of the evaporation process from the sand columns saturated with $0.5,1.0,1.5$ and $2.5 \mathrm{M}$ are almost the same (because in all cases crust forms at the surface that controls the drying process). This conclusion is in-line with the results presented recently by Bergstad and Shokri [2016]. They showed that the evaporative mass losses from porous media saturated with salty solutions with varying wettability conditions were nearly the same regardless of the wettability condition due to the effect of the presence of precipitated salt at the surface.

To have a closer look at the precipitation dynamics, we visualized salt precipitation at the surface during drying of sand pack at the micro-scale with typical results presented in Figure 3(a).

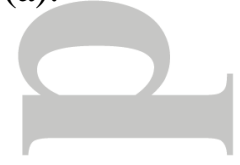

The microscopic images reveal that the salt crust formed at the surface of the porous media is itself porous and evolves in a highly dynamic way due to the complex interplay of crystallization and evaporation at the crystal-liquid, crystal-crystal, liquid-air, and the crystalair interfaces [Shahidzadeh et al., 2015]. This is in agreement with the results reported recently by Dai et al. [2016] showing that $\mathrm{NaCl}$ "preferentially precipitates in cubic-shaped crystals that are packed heterogeneously to form a very porous structure". The recorded images also indicate that formation of salt does not necessarily clog the pores; the continued 
growth of salt crystals above the precipitated salt indicates further water evaporation with vaporization occurring at the salt surface. Microscopic analysis suggests that the presence of porous salt at the surface causes top-supplied creeping of the solution, feeding the growth of subsequent crystals. Our results suggest that the precipitated salt at the surface is an ever changing porous media with its own unique properties and chemical interactions as long as the surface of the underlying porous sand packing remains wet.

In the literature, the drying curve from porous media saturated with salt solutions is normally described in terms of three stages [Jambhekar et al., 2015]: The first stage includes a decreasing drying period (as a result of increasing salt concentration at the surface) when the drying rate is relatively high followed by a transition period (second stage) to a stage when the evaporative flux is much smaller than the first stage limited by the vapour diffusion through the salt crust (third stage). However, our observations suggest that this description needs revising: an additional stage should be included (at least for the cases studied in this article) in which the evaporation rate is largely controlled by liquid transport and evaporation through the evolving porous salt layer formed at the surface.

\subsection{Evolving precipitated salt layers at the surface and their effect on the evaporation}

rate

Based on our observation and the results presented in Figure 1 and 2, we propose a characteristic curve (presented in Figure 3(b)) to describe the various stages of saline water evaporation from porous media. Phase 1, A-B represents the stage during which the evaporation rate is largely dependent on external conditions (e.g. ambient temperature, relative humidity, radiation) and the saturated vapour pressure of the solution influenced by the salt concentration. The decreasing evaporation rate during this stage is due to the increasing salt concentration close to the surface (which reduces the vapour pressure and thus 
the driving force for evaporation). Furthermore, the formation of the salt crust is initially causing an increased mass transfer resistance for the liquid to reach the evaporation surface. However, when the evolving salt layer covers a substantial portion of the surface of the salt column, the evaporation rate ceases to decrease further (as evidenced by the results of this study). This marks the end of phase 1. During Phase 2 (B to $\mathrm{C}$ in Figure 3 (b)), the evaporation rate is relatively constant, because the precipitated salt is porous and remains wet (fed by capillary flow). Further precipitation onto this salt layer and the forming complex dendritic structures increase the surface area available for evaporation. While the driving force for evaporation continues to decrease, it is approximately counterbalanced by this increased surface area, hence the relatively constant rate. In most cases (Figure 2) this phase is observed from about 4 days until about 8 days and is quite similar to the so-called stage- 1 evaporation from porous media saturated by pure water [Shokri and Or, 2011]. During this phase, the salt crust does not obstruct the pathways connecting the saturated zone to the sand surface and the evaporative demand is largely met by the liquid transport through the evolving porous salt crust; Phase 3 (C-D in Figure 3 (b)) represents a stage during which the capillary liquid supply through the salt crust becomes disrupted, resulting in gradual drying of the salt layer, which in turn reduces the evaporation rate. This phase can be considered as a transition phase from evaporation controlled by the wet crust to evaporation controlled by the dry crust (Phase 4, D-onward) during which the flux is limited by the vapour diffusion through the dry precipitated salt. Similar transition periods are commonly observed from the stage-1 evaporation (a period when the surface of porous media remains wet) to stage-2 evaporation (a period when the porous media surface is dried and the process is controlled by vapour diffusion through a dry surface layer [Shokri and Or, 2011]). 


\subsection{Thermal signature of the contribution of precipitated salt to the evaporative rate}

One of the key messages of the present work is the significant role of water evaporation through the wet precipitated salt during evaporation; a process that must be taken into account for a reliable description and prediction of saline water evaporation from porous media. As discussed in other studies (e.g. Veran Tissoires et al. [2014]), salt crystallization in drying porous media is a dynamic process in which a growing crystal can consume the supersaturation which may lead to dissolution of nearby crystallites. This influences the dynamics of surface temperature during evaporation which is investigated in this section. To do so, high resolution thermography was used to delineate the thermal signature of saline water evaporation from porous media. Figure 4 (a) shows the evolution of surface temperature by the minute, starting at 2.6 day after commencing the experiment alongside a photograph of the salt crust within this period (where the surface is entirely covered by the precipitated salt).

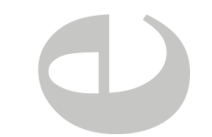

Rapid surface temperature fluctuations were found to be a characteristic behaviour coinciding with phase 2 of the saline water evaporation in all cases examined in our experiments. As explained earlier, during this period, the surface is visibly covered by a salt crust but the evaporation rate is relatively constant and higher than the flux expected if it were controlled by the vapour diffusion through the dry crust. During phase 2 , the surface temperature changes rapidly, as shown in Figure 4(a) resulting in the appearance and disappearance of "cold-spots". The figure shows temperature changes as much as $\sim 2^{\circ} \mathrm{C}$ every minute. Such a rapid fluctuation was not observed when the sand column was saturated by pure water; see Figure S1 in the supporting information. Additionally, it should be noted that the rapid temperature fluctuation at the surface was only observed during phase 2 of saline water 
evaporation and it was not observed during phase 1, 3 and 4 proposed in Figure 3 (see Figures S2, S3 and S4 in the supporting information).

The appearance of localized cold spots (a phenomenon that is not observed during pure water evaporation from porous media) is associated with preferential evaporation at different locations through the precipitated salt where some of the incoming energy is consumed for liquid vaporization. Preferential evaporation increases the concentration of salt locally, which in turn leads to an increased rate of salt precipitation shortly after the occurrence of the cold spot. Since precipitation releases heat, the temperature at the cold spot should subsequently increase at this locus. This complex interplay between evaporation and precipitation leads to the observed temperature oscillations in Figure 4 (a). This experimental data provides additional confirmation for the contribution of precipitated salt to the evaporative mass losses. This analysis reveals the need to develop more sophisticated models to describe the evolution of porous salt crust at the surface and its contribution to the evaporation process (Malmir et al., 2016).

In addition to the microscopic analysis of the salt effects on surface temperature dynamics with the associated preferential evaporation from the evolving crust, we studied the impact of the presence of salt on the surface temperature at the macroscopic scale. To do so, we calculated the average surface temperature at different times as a function of the initial salt concentration. Figure 4 (b) shows that in the early stages of the process, the average surface temperature increases with initial salt concentration. This correlates well with the reduced evaporation rates shown in Figure 2 and schematically depicted in Figure 3 (b). This finding shows that the presence of salt influences the surface temperature, which is not normally considered in hydrological modelling or water and energy balance analysis. Higher 
temperature as a result of the presence of salt may impact biological activities and biodiversity in soil.

\section{Summary and conclusions}

Our results confirm that precipitation of salt at the surface does not necessarily clog the pores and evaporation continues via water flow through the evolving porous crust structure. This mechanism plays a central role in defining the evaporative fluxes from porous media saturated with $\mathrm{NaCl}$ solutions. Without clear understanding of how the structure of the crystalized salt evolves at the surface during evaporation and how it limits the corresponding water flow, modelling efforts will largely rely on adjusting parameters which oversimplifies this process and masks the true physics governing saline water evaporation from porous media. Thermal imaging together with simultaneous imaging of the surface precipitation patterns and recording the drying dynamics enabled us to extend our physical understanding of the process. We have proposed a conceptual evaporation curve that highlights different phases with the corresponding dominant mechanisms in each phase. Additionally, we discussed the complex temperature fluctuations at the surface due to efflorescence, which has rarely been illustrated in the past. Also, our results confirmed higher surface temperatures in the case of higher initial salt concentrations. This finding suggests that soil salinity not only affects crop production, vegetation etc. but also influences surface temperature, which may be relevant to biological activities in soil.

This study highlights the importance of the role of the precipitated salt on water flow and subsequent evaporation dynamics and we believe that future research must be directed toward further analysis and characterisation of how exactly the structure of the precipitated salt evolves during drying. This ultimately determines the dynamics of the evaporative water 
losses and will be relevant to modelling of many hydrological processes, land-atmosphere interaction and water management.

\section{Acknowledgement}

We gratefully acknowledge funding by the Leverhulme Trust to support this research (RPG2014-331) and the equipment funding from the Royal Society (RG140088). The data used in this manuscript will be available freely via sending a request to the corresponding author. The

first and last author would also like to acknowledge the contribution and cooperation of Delphi Everest Dana Shokri-Kuehni during this research.

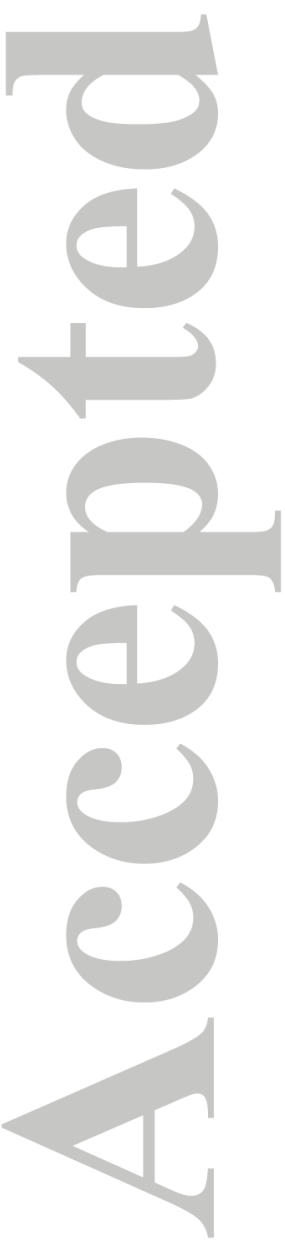




\section{References}

Aminzadeh, M., and D. Or (2014), Energy partitioning dynamics of drying terrestrial surfaces, J. Hydrol., 519, 1257-1270.

Bergstad, M., N. Shokri (2016), Evaporation of $\mathrm{NaCl}$ solution from porous media with mixed wettability, Geophys. Res. Lett., 43, 4426-4432.

Börnhorst, M., P. Walzel, A. Rahimi, A. Kharaghani, E. Tsotsas, N. Nestle, A.Besser, F. Kleine Jäger and T. Metzger (2016), Influence of pore structure and impregnation-drying conditions on the solid distribution in porous support materials, Drying Technol., 34(16), 1964-1978, DOI: $10.1080 / 07373937.2016 .1147048$.

Dai, S., H. Shin, and J.C. Santamarina (2016), Formation and development of salt crusts on soil surfaces, Acta Geotech., 11, 1103-1109. doi:10.1007/s11440-015-0421-9.

Desarnaud, J., H. Derluyn, J. Carmeliet, D. Bonn, N. Shahidzadeh (2014), Metastability limit for the nucleation of $\mathrm{NaCl}$ crystals in confinement, J. Phys. Chem. Lett., 5(5), 890-895.

Eloukabi, E., N. Sghaier, S. Ben Nassrallah, and M. Prat (2013), Experimental study of the effect of sodium chloride on drying of porous media: The crusty-patchy efflorescence transition, Int. J. Heat Mass Transfer, 56, 80-93.

Guglielmini, L., A. Gontcharov, A. J. Aldykiewicz Jr., and H. A. Stone (2008), Drying of salt solutions in porous materials: Intermediate-time dynamics and efflorescence, Phys. Fluids, 20, 077101, doi:10.1063/1.2954037.

Gupta, S., P.H. Huinink, M. Prat, L. Pel, and K. Kopinga (2014), Paradoxical drying of a fired-clay brick due to salt crystallization, Chem. Eng. Sci., 109, 204-211.

Haghighi, E., and D. Or (2015), Thermal signatures of turbulent airflows interacting with evaporating thin porous surfaces, Int. J. Heat Mass Transfer, 87, 429-446. 
Huinink, H. P., L. Pel, and M. A. Michels (2002), How ions distribute in a drying porous medium: A simple model, Phys. Fluids, 14, 1389-1395,doi:10.1063/1.1451081.

Jambhekar, V.A., R. Helmig, Natalie Schroder, N. Shokri (2015), Free-flow-porous-media coupling for evaporation-driven transport and precipitation of salt, Trans. Porous. Med., 110(2), 251-280.

Malmir, H., M. Sahimi, and M.R. Rahimi Tabar (2016), Microstructural characterization of random packings of cubic particles, Sci. Rep. 6, 35024, doi:10.1038/srep35024.

Nachshon, U., E. Shahraeeni, D. Or, M. Dragila, and N. Weisbrod (2011a), Infrared thermography of evaporative fluxes and dynamics of salt deposition on heterogeneous porous surfaces, Water Resour. Res., 47, W12519, doi:10.1029/2011WR010776.

Nachshon, U., N. Weisbrod, M. Dragila, and A. Grader (2011b), Combined evaporation and salt precipitation in homogeneous and heterogeneous porous media, Water Resour. Res., 47, W03513, doi:10.1029/2010WR009677.

Norouzi Rad, M., N. Shokri, and M. Sahimi (2013), Pore-scale dynamics of salt precipitation in drying porous media, Phys. Rev. E, 88, 032404.

Norouzi Rad, M., N. Shokri, A. Keshmiri, and P. Withers (2015), Effects of grain and pore size on salt precipitation during evaporation from porous media: A pore-scale investigation, Trans. Porous. Med., 110(2), 281-294.

Ott, H., M. Andrew, J. Snippe, and M. J. Blunt (2015), Microscale solute transport and precipitation in complex rock during drying, Geophys.Res. Lett., 41, 8369-8376, doi:10.1002/2014GL062266.

Rodriguez-Navarro, C., and E. Doehne (1999), Salt weathering: Influence of evaporation rate, super saturation and crystallization pattern, Earth Surf. Processes Landforms, 24, 191-209.

Sghaier, N. and M. Prat (2009), Effects of efflorescence formation on drying kinetics of porous media, Transp. Porous Med., 80, 441-454, doi: 10.1007/s11242-009-9373-6. 
Shahidzadeh, N., M.F.L. Schut, J. Desarnaud, M. Prat, and D. Bonn (2015), Salt stains from evaporating droplets, Sci. Rep.5, 10335; doi: 10.1038/srep10335.

Shokri, N. (2014), Pore-scale dynamics of salt transport and distribution in drying porous media, Phys. Fluids, 26, 012106.

Shokri, N., and D. Or (2011), What determines drying rates at the onset of diffusion controlled stage-2 evaporation from porous media?, Water Resour. Res., 47, W09513.

Shokri-Kuehni, S.M., E. Bou-Zeid, C. Webb, and N. Shokri (2016), Roof cooling by direct evaporation from a porous roof layer, Energy and Buildings, 127, 521-528.

Shokri-Kuehni, S.M., M. Norouzirad, C. Webb, N. Shokri (2017), Impact of type of salt and ambient conditions on saline water evaporation from porous media, Adv. Water Resour., 105, 154-161.

Suweis, S., A. Rinaldo, S. E. A. T. M. Van der Zee,E. Daly, A. Maritan, and A. Porporato (2010), Stochastic modelling of soil salinity, Geophys. Res. Lett., 37, L07404, doi:10.1029/2010GL042495.

Veran-Tissoires, S., and M. Prat (2014), Evaporation of a sodium chloride solution from a saturated porous medium with efflorescence formation, J. Fluid Mech., 749, 701-749, doi:10.1017/jfm.2014.247. 


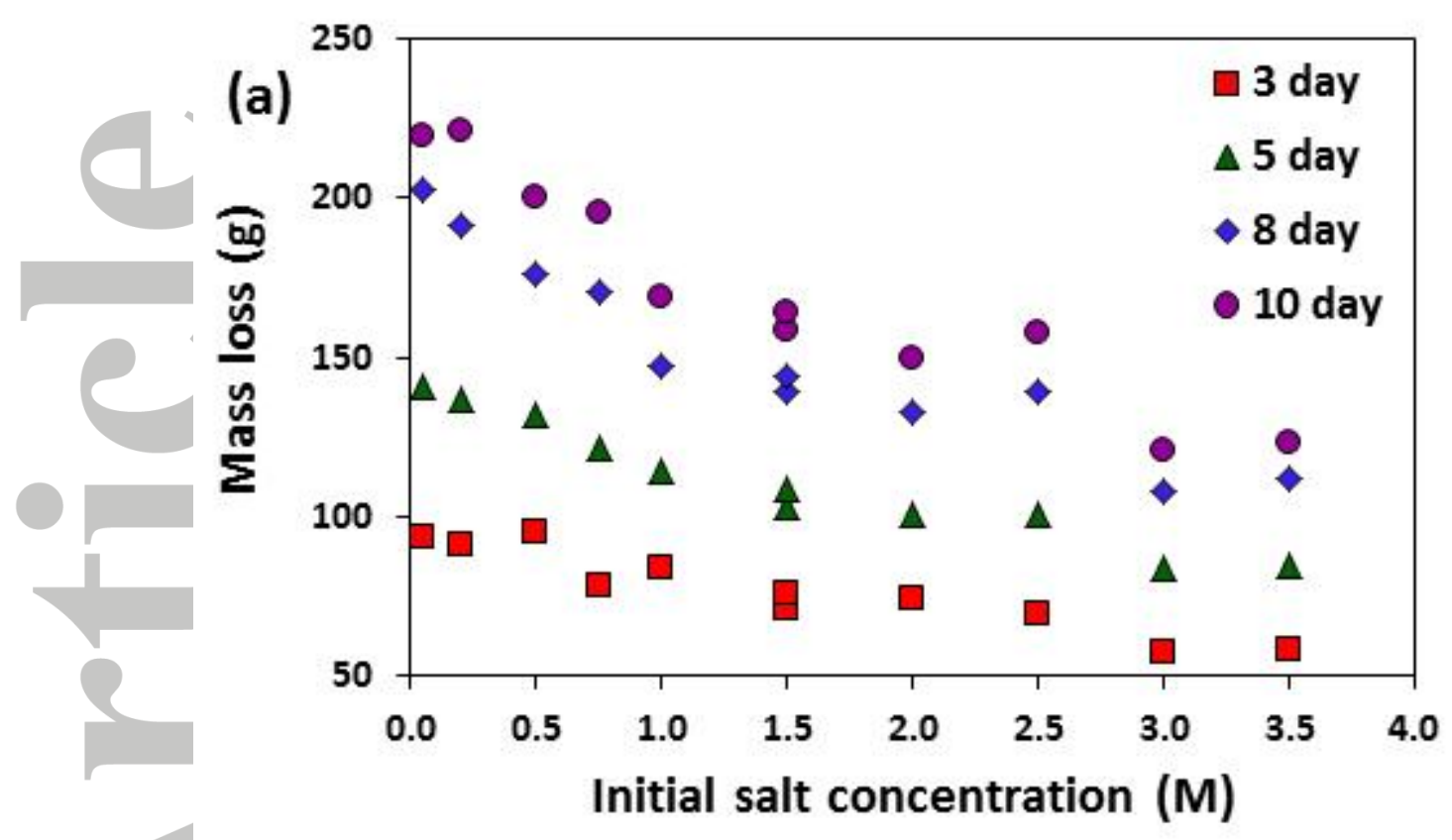

(b)
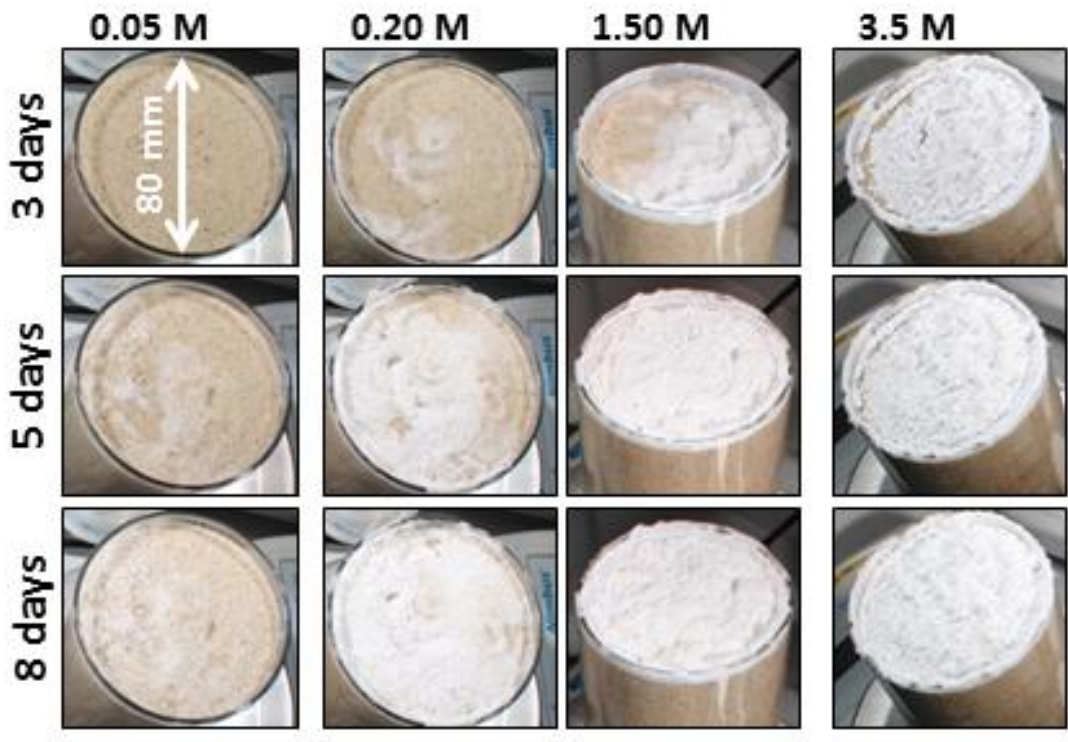

Figure 1. (a) Measured cumulative evaporative losses at different times from the start of experiments as a function of the initial salt concentration. (b) Typical examples of precipitation patterns at various stages, for solutions with initial salt concentrations of $0.05,0.2,1.5$ and $3.5 \mathrm{M}$. 


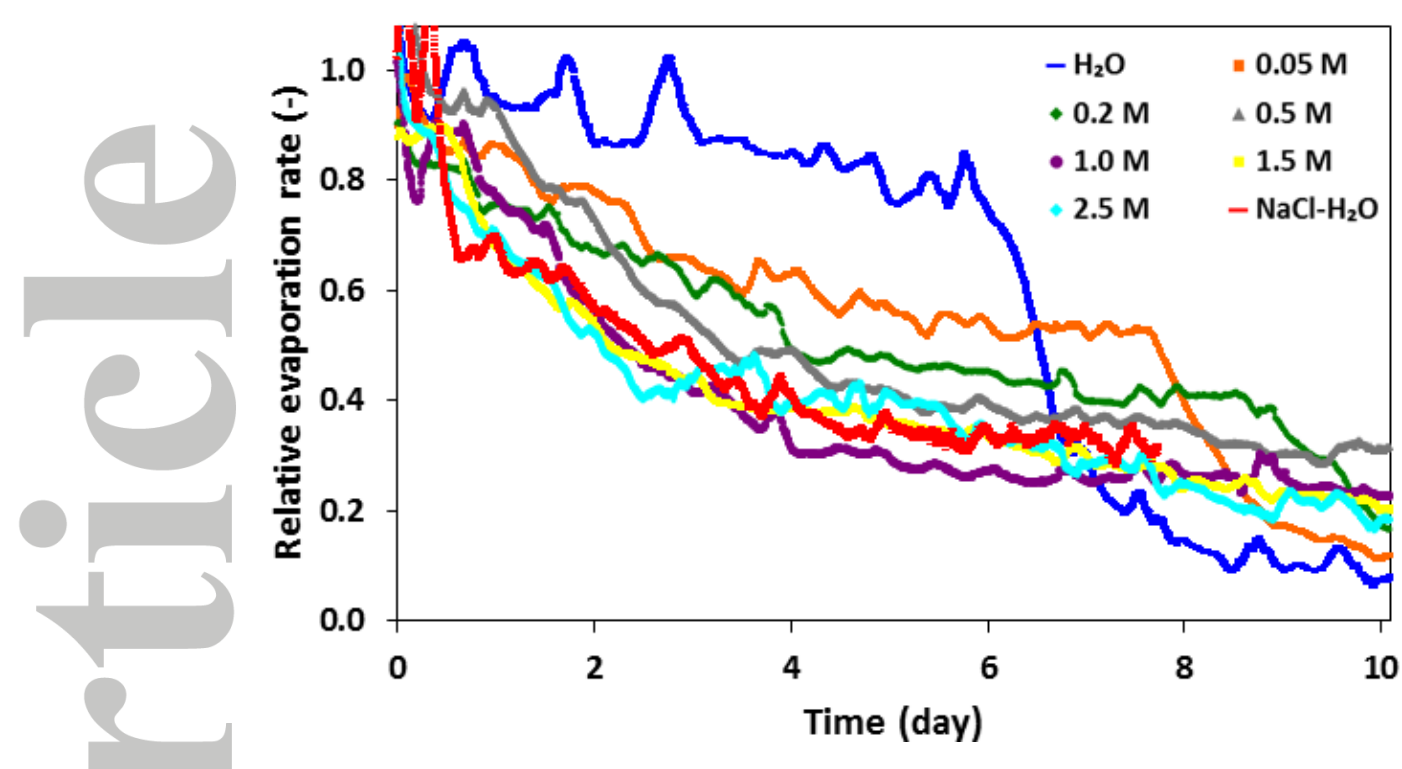

Figure 2. Relative evaporation rate (defined as the evaporation rate divided by the potential evaporation rate) versus time as influenced by the initial salt concentrations indicated in the legend. Also presented is the evaporation curve measured from the columns saturated with pure water $\left(\mathrm{H}_{2} \mathrm{O}\right.$ in the legend) as well as the column packed with salt grains saturated by salt solution $\left(\mathrm{NaCl}-\mathrm{H}_{2} \mathrm{O}\right.$ in the legend). The observed fluctuations in the early stages might be due to the fluctuations in ambient temperature and relative humidity. 


\section{Sand $+\mathrm{NaCl}+\mathrm{H}_{2} \mathrm{O}$}
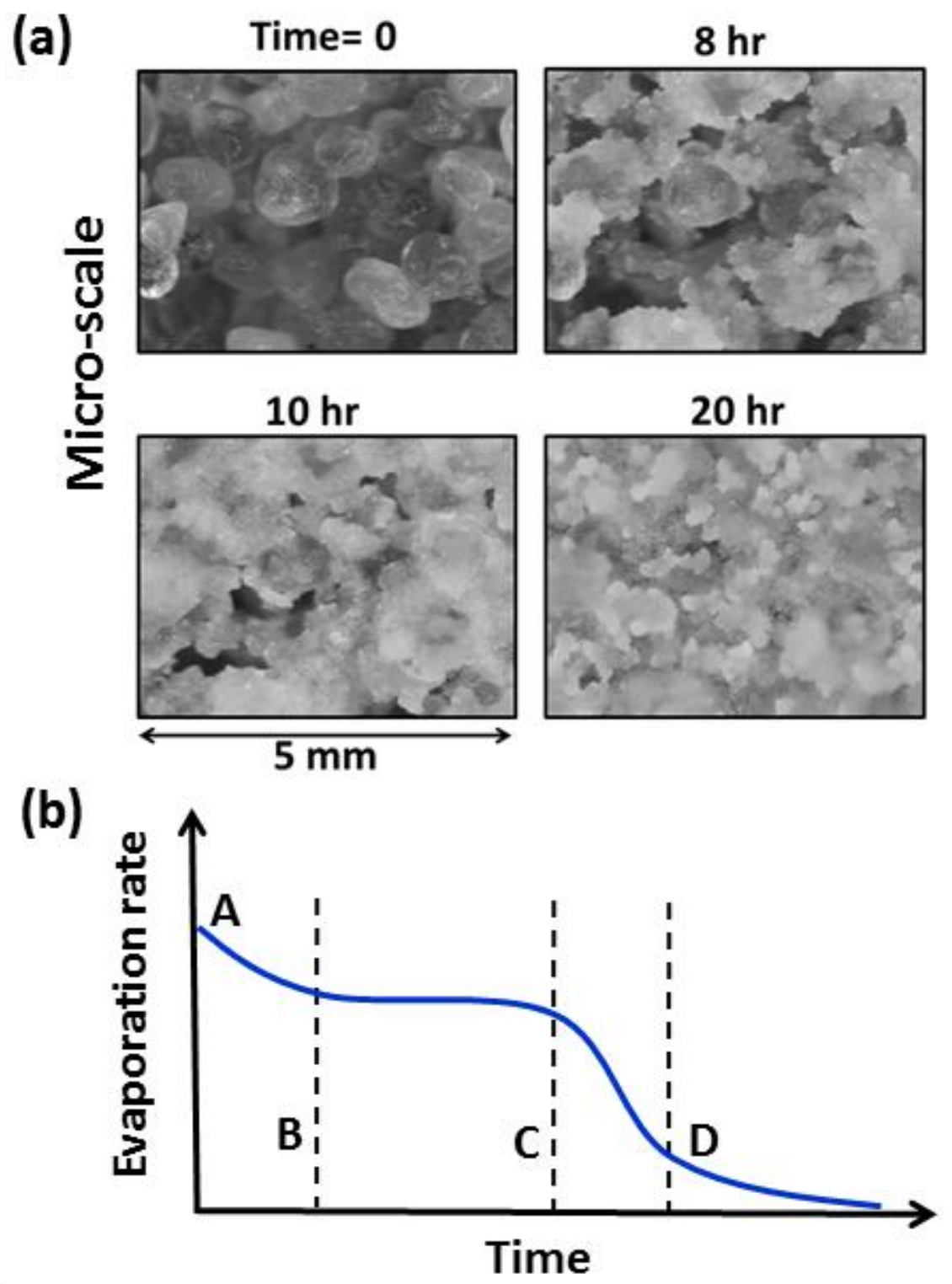

Figure 3. (a) Microscopic images illustrating precipitation dynamics at the surface of sand grains saturated with saline solution. Numbers at top indicate the elapsed time from the onset of the experiment. As time passes, salt crystals appear at the surface (distinguished by the bright colour). (b) The schematic illustrates conceptually the typical trend of the saline water evaporation from porous media with the following stages: Phase A-B: Increase in salt concentration and formation of salt crust govern the initial decrease in the evaporation rate. Phase B-C: Drying rate is largely controlled by liquid transport through the evolving porous salt crust. During this phase, the precipitated salt remains wet. Phase C-D: Gradual drying of the precipitated salt at the surface significantly decreases the evaporation rate. Phase D-onward: Vapour diffusion through the sand and the dry precipitated salt limits the evaporation rate. 

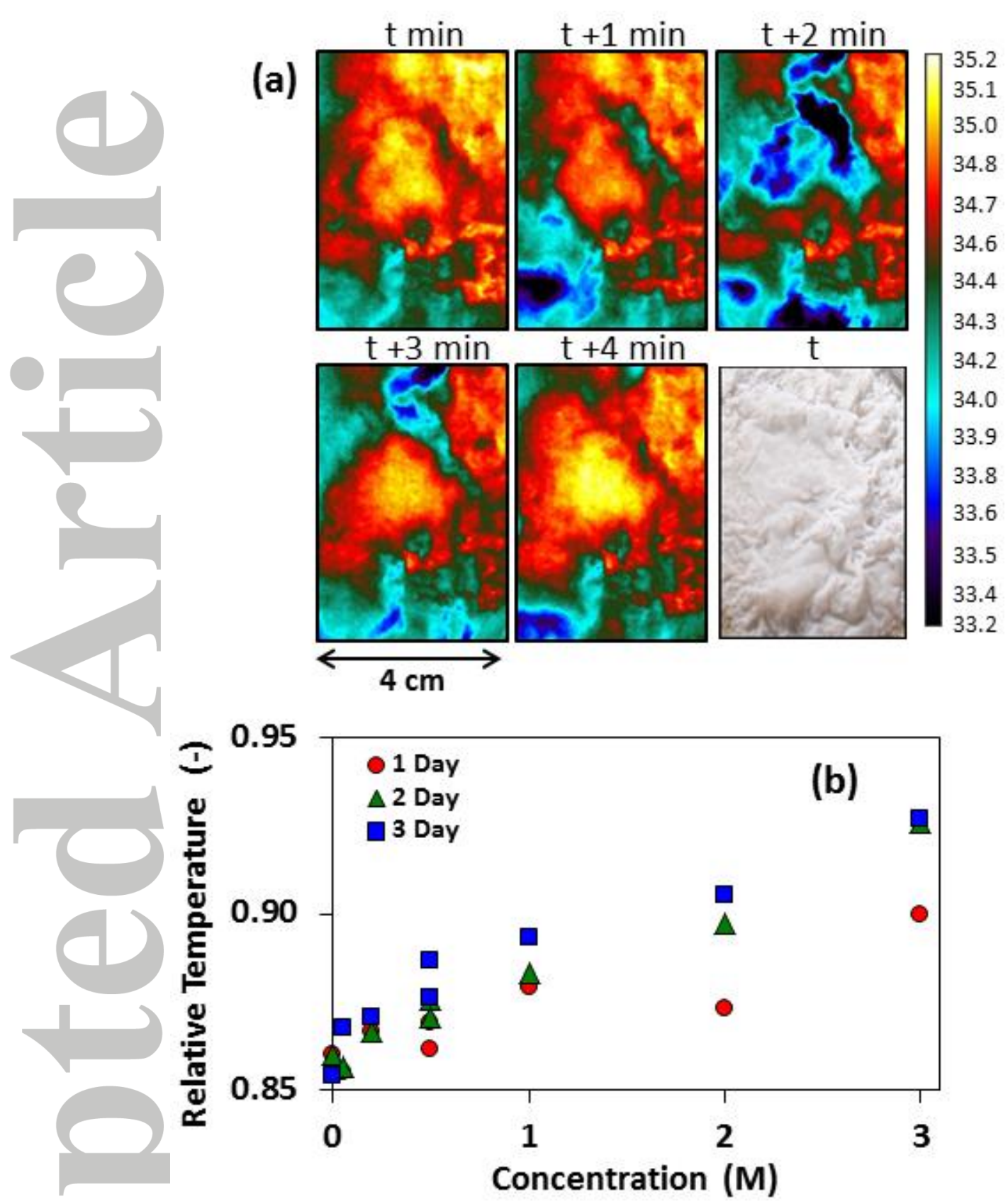

Figure 4. (a) Fluctuation of salt crust temperature at the surface of a sand column. The visualized salt crust has an area of $24 \mathrm{~cm}^{2}$. The temperature of the surface was recorded every minute. The colormap indicates temperature in centigrade. The closer to blue (darker colour) the lower the temperature. The initial $\mathrm{NaCl}$ concentration was $2.5 \mathrm{M}$ and $t$ stands for time $=2.6$ day from the start of the experiment. The last image shows the actual salt crust for which the temperature fluctuations were recorded. (b) Average surface temperature at different stages of the experiment (indicated in the legend) as a function of the initial salt concentration. Temperature was scaled by a reference temperature measured at the surface of the bench in each round of experiments. 